Wood, R., Litherland, B., and Reed, E. (2019) Cultural Studies.

\title{
Girls Being Rey: Ethical Cultural Consumption, Families and Popular
}

\section{Feminism}

This paper argues that consumers of popular culture engage in practices of 'ethical cultural consumption', whereby the consumption of cultural texts is imagined as having the potential to 'do good' both individually and socio-politically. The paper explores data from an online questionnaire and drawing activity with girls aged 510 and their parents on the experience of cosplaying (costume playing) as Rey from the contemporary Star Wars trilogy. Imagined as a 'girl who can do anything', Rey represents a new kind of popular feminist hero and role model for girls, enabling a degree of critique of normative gendered role models for children. 'Being Rey' also represents a deterministic project through which parents aim to cultivate the 'right' kind of girls, seeking to instil the resilience to 'cope' with unknown futures. More than a purely individual project, we argue that parents invest in an individualised idea of doing 'good' through consumption, drawing on a notion of the consumer as a political actor with the power to affect social change. Investigating the project of participating in and consuming culture 'ethically' allows for an exploration of what it means to 'be political' and 'do good' as a consumer in neoliberalism.

Keywords: popular feminism; costume play; ethical consumption; participatory culture; girls; neoliberalism; families

Following the release of Star Wars: The Force Awakens (Abrams, 2015), images of girls participating in Rey 'cosplay' (costume play) proliferated on social media. Described in a Buzzfeed article as 'adorable' 'tiny' Reys, the authors concluded that the character had 'given the millions of little girls who saw The Force Awakens an amazing female role model' (Flaherty \& Rackham, 2016). There is a strong affective dimension to the sharing 
Wood, R., Litherland, B., and Reed, E. (2019) Cultural Studies.

and liking of such images, centring on the notion that cosplaying as Rey and other positive, visible media role models allows children (often girls) to imagine their selves and futures in new, enabling and empowering ways. As one fan wrote in the popular press, 'My heart warms with every tweet, comment, or picture I see of young girls dressing up as Rey. A whole new generation of fans... who see themselves as the heroine' (White, 2016).

In the discourse surrounding these images, girls who participate in costume play become loaded with ideological significance. This draws in part on Rey's central role in Disney's relaunched Star Wars franchise since 2015. As a questing heroine with mysterious origins and powerful control of the 'Force', Rey has been framed as a 'girl who can do anything' (Ratcliffe, 2016). As an endlessly 'flexible and self-realizing' subject (Harris, 2004, p. 2), Rey can be contextualised within a neoliberal version of popular feminism: a contemporary 'zeitgeist' (Banet-Weiser, 2015), also referred to as 'neoliberal feminism' (Rottenberg, 2018) and incorporating much of 'postfeminism' (Gill, 2016; Gill, 2007; McRobbie, 2009; for an overview of these three terms see BanetWeiser, Gill \& Rottenberg, 2019). Popular feminism celebrates the achievements of girls and women in an often individualised and depoliticised context (Gill, 2016; Rottenberg, 2018), placing the onus on girls and women to be responsible for their own success or failure. This focus frequently obscures structural understandings of gender inequality and feminist politics.

Disney's promotion of Rey, the fan reception of the character and related merchandise (Scott, 2017; Brown, 2017; de Bruin-Molé, 2018), and the celebration of girls' Rey cosplay on social media, can be squarely situated within this zeitgeist. Rey has been described as a 'transformational' and 'empowering' character, a 'game changer for little girls around the world' (Karvelas, 2015). Rey's ability to 'do anything' makes her 
Wood, R., Litherland, B., and Reed, E. (2019) Cultural Studies.

'inspirational' to girls and young women (Ratcliffe, 2016). The implication of this framing is that the (imagined) girls in the audience will develop the resilience (Gill \& Orgad, 2018) to overcome sexism and inequality, and become the idealised, flexible (Harris, 2004) heroine of their own story.

This paper emerges from the need to understand what dressing as this 'girl who can do anything' means in the everyday lives of girls and their families. Using an online questionnaire and drawing activity, the project sought to interrogate girls' Rey costume play from the perspective of families, gathering data from nine families on the everyday experience and significance of wearing a Rey costume. The aim of the project was to move beyond the affective and symbolic draw of social media posts of girls in Rey cosplay in order to gain a deeper understanding of the role that dressing as a character like Rey might play in the everyday lives and identities of parents, girls and families.

We refer to participants' 'costume play', rather than using the portmanteau 'cosplay', throughout the paper as a way of noting the multiple discrete but intersecting practices involved. Some of the families did participate in fannish practices commonly referred to as 'cosplay' (Lamerichs, 2018), such as wearing a Rey costume to a comic con or film screening and sharing images using cosplay hashtags. Others, however, wore the costume only to parties, school events and/or at home as part of 'dressing up' play. This suggests that Rey costume play continues and develops established childhood norms surrounding 'dressing up' events and play (for example see Chudacoff, 2007, p.55). We argue that dressing as Rey is one way in which girls and their families negotiate the meanings and contradictions surrounding young femininities in popular feminism.

Participants demonstrated a clear awareness of Rey's brand, repeatedly identifying in drawings and written responses core qualities of bravery, strength and kindness. Costume playing as Rey is one way in which families undertake collective 
Wood, R., Litherland, B., and Reed, E. (2019) Cultural Studies.

identity work, constructing and performing themselves as the 'right' kind of family, raising the 'right' kind of girl: one who is both strong and resilient, and appropriately feminine. This represents a form of 'parental determinism' (Lee, 2014) wherein parents cultivate individually responsible and resilient future citizens (Vincent and Ball, 2007), an ethos reflected in the individualised politics of popular feminism and related incitements to participate in consumer capitalism.

This paper contends that these forms of participation are indicative of an emerging set of consumer preferences and practices that we refer to as ethical cultural consumption. Families' operate within a cultural context in which media representation, and the consumption of those texts, is understood to have the power to 'do good' at both an individual and social level. Specifically for our study, ethical cultural consumption choices are mobilised as part of a moral project of 'building a better future' for girls and young women, although exactly how this will be achieved is ill-defined in parents' accounts. Here, consuming 'good' culture 'ethically' is framed as part of a project of raising 'better' daughters, being a better kind of family, and creating a fairer and more equal world.

This paper explores the highly individualised politics of ethical cultural consumption, and their resonance with popular feminist, neoliberal rationalities of social change as mobilised primarily by individual choices. As scholarship has emphasised, though, recent shifts on the terrain of popular feminism suggest possibilities for the (re)emergence of a form of collectivist politics, pushing against the notion of a neoliberal orthodoxy of the individual (Banet-Weiser, Gill \& Rottenberg, 2019; Wood \& Litherland, 2018). The \#MeToo movement, with its focus on the intersections of sex and power and collective participation, seemingly represents 'a challenge to the highly individualised nature' of popular understandings of sexism and gender inequality (Gill and Orgad, 
Wood, R., Litherland, B., and Reed, E. (2019) Cultural Studies.

2018b, p.6). Although our research with families speaks to deeply individual anxieties around parenting girls in ways that are 'right' and 'good', the framework of ethical cultural consumption also allows us to capture participants' understandings of responsibility beyond the individual. In the analysis that follows, we draw out those moments that speak to this potential 'redoing' of feminist politics in neoliberalism (Baer, 2016).

In the following section we outline the project's methodology and introduce the data from which our understanding of ethical cultural consumption emerges. These parts of the data show families endeavouring to do 'good' and effect individual and social change through the consumption of culture, including Rey. Following this, we explore the concept of ethical cultural consumption in some detail, considering what it means for media representations to be 'ethical', why media corporations like Disney might be invested in framing their responsibility to produce 'good' representations, and how ethical cultural consumption may, or may not, intersect with material forms of ethical consumption. We then turn back to the data for a closer consideration of the role of gender in Rey costume play, drawing out themes which show families' efforts to manage and negotiate ideas of contemporary girlhood, before examining the transformation of everyday girlhood through 'being Rey'.

\section{Methodology}

Data was collected through an online questionnaire in 2018, allowing us to engage with a geographically diverse group whose overall size it is not possible to estimate. Purposive sampling was used; participants were the main carer, parent, or guardian of a girl aged 515 who had dressed as Rey from Star Wars. Nine families were recruited through online networks, social media posts, and flyer distribution at Comic Cons in Manchester and 
Wood, R., Litherland, B., and Reed, E. (2019) Cultural Studies.

Birmingham, UK. Additionally, by searching posts on popular hashtags such as \#reycosplay, \#reycostume, \#starwarskid and \#starwarsfamily, potential participants were identified and approached directly on Twitter and Instagram. The girls ranged in age from 5 to 10 years old. Five participants listed their country of residence as England or the UK, one participant resided in Italy, one in the USA, and two in Germany. Most participants described their family's race and ethnicity as some combination of white, Caucasian, English, or British (6), and two participants described their family's race and ethnicity as “mixed".

Although this sample is small, the data collected was rich and multi-layered. We sought unique insights into family media consumption rather than large-scale generalizability (Braun and Clarke, 2013; Smith, 2017; Steinmetz, 2004); this focus allows us to highlight directions for future study and suggested approaches for exploring this type of consumption.

The questionnaire was designed to be co-completed by girls and their parent, carer or guardian, and had three elements: a drawing task in which girls were asked to draw a picture of themselves dressed as Rey, 4 questions for girls about Rey, and 13 questions for parents about Rey and their daughter. The drawing task included the direction to participants to talk to their daughters about their drawing and we provided space for participants to upload this image along with any comments (Bland, 2012; Einarsdottir, 2007; Einarsdottir, Dockett and Perry, 2009; Reason, 2010). We did not seek to impose full anonymity and invited girls to sign their drawings with their first name and age, thus enabling children to maintain a sense of ownership over their drawing (Reason, 2010). Five girls chose to sign their names. Beyond this, families are referred to anonymously by a designated number throughout this paper. 
Wood, R., Litherland, B., and Reed, E. (2019) Cultural Studies.

Inclusion of children in the research required a parent's consent for their children to participate; the responses reported from girls in this research were, therefore, filtered through their parents (Punch, 2002, p.323-325). We believe, however, that the concept of an unmediated children's 'voice' is already a fraught one (Gallagher, 2009; Komulainen, 2007), and children's expression and communication can be understood as necessarily collaborative and interpretive. The filtering which may have shaped the recorded responses of these girls does not undermine their value or meaning. The research was interested in the ways that families co-constructed family identity and articulated their values.

\section{Cultural Consumption as Parenting Project}

In both popular discourse and for the families who participated in the research, Rey is seen to be a character who helps navigate the girls through imagined and real opportunities and dangers. Cultural consumption within the family unit can be a resource through which parents attempt to assert a feeling of control over future outcomes, something Lee (2014) describes as parental determinism. As Vincent and Ball (2007) argue, the child is understood as a 'project', able to be moulded and improved by parents' 'concerted cultivation' efforts. Star Wars, then, belonged to a wider set of cultural texts and objects which were used to help facilitate this 'moulding'. Seeking out and supporting cultural texts with the 'right' kind of messages was critical:

I choose books with female characters who are independent and strong (Family 4)

I've [tried] to choose good examples when choosing books and films (Family 8) We have tried to make sure she sees plenty of films with a female girl protagonist who encounters adventure (Family 3) 
Wood, R., Litherland, B., and Reed, E. (2019) Cultural Studies.

Families also mentioned Disney films Moana (Musker \& Clements, 2016) and Tangled (Greno \& Howard, 2010), and Wonder Woman (Jenkins, 2017) and Hidden Figures (Melfi, 2016). Books like Goodnight Stories for Rebel Girls and Women Who Changed the World were also discussed.

The representations within chosen 'good' media texts are not left to speak for themselves by parents. Instead, they are starting points for discussion, integrated into the work of parenting and family life:

I had always loved Jane Eyre as a character and recently sat and watched the modern film version with my daughter. We talked about her inner strength and how she remained kind to others despite her tragic past... rather like Rey! (Family 8)

Using films such as Tangled with a central heroine figure to stimulate discussion about determination ... we used the 'women that changed the world' book to stimulate discussion about female role models and scientists (Family 9)

Positive representations of women were explicitly brought out by parents through discussion with their daughters, emphasising 'ideal' girl qualities. Parents also appeared to see their daughters as active agents in the process of consuming and participating in 'good' texts, with seven of the nine families stating that dressing as Rey was an activity instigated by their daughters.

More than simply an individual project, the consumption of Rey and other representations articulates a desire to influence and affect cultural and social change through their daughters, albeit in an individualised way. One parent stated this explicitly: 'I believe if we as parents can instil a good foundation in how we bring up our daughters and how they see themselves, change will come' (Family 6). For other parents this was more implicit, with an emphasis on role models for girls who 'speak out' and 'overcome 
Wood, R., Litherland, B., and Reed, E. (2019) Cultural Studies.

challenges' (Family 1) and 'stand up' for what they 'believe in' (Family 2). As Family 9 stated when discussing challenges facing girls today, 'I believe that this is changing, but it is taking time'. The link between an individual consumption project and broader social and political goals is somewhat vague, encapsulated by the imprecise assurances that 'change will come' and it will 'take time'. This leap from individualised achievements to vaguely drawn political hopes for equality is emblematic of popular feminism (Gill, 2016).

All parents except one had shared images of girls' Rey costumes on social media. One parent remarked that social media followers were 'fascinated that she doesn't want to be a princess' (Family 5), a theme we return to below. Another related that 'my friends told me... her attitude showed pride' (Family 4). Family 2 were very active on social media, remarking on the 'many likes, comments and shares' their daughter receives for costume play. These comments helped parents affirm that they were making the 'right' parenting choices, but they also show a broader desire to shape the terrain of reception for Rey and other such 'good' representations. They suggest families' desire to communicate the good that Rey is doing in their daughters' lives, and, more implicitly, their attempts to carve out space for the social and political value of such representations.

It is this ideological investment in the value and possibility for social change stemming from their considered cultural consumption which characterises what we are describing as the 'ethical' element of this family consumption. In the following sections we explore the significance of what it means for cultural consumption to be 'ethical', before returning again to the data to consider the role of gender and everyday transformation in families' practices of Rey costume play.

\section{The 'Ethics' of Representation}


Wood, R., Litherland, B., and Reed, E. (2019) Cultural Studies.

The consumption practices undertaken by these families happen in a context where media representation is increasingly framed as a question of ethics. By this we mean that 'better' - more diverse, more positive, more informed - representations of a range of previously under- or poorly- represented identities is seen as having the potential to do individual and social 'good'. Of course, this principle does not come without often aggressive resistance from consumers who would prefer the status quo to remain uncontested (Hunt, 2018; Blodgett and Salter, 2018). If articulated at all, the work that representation is claimed to do ranges widely, including anything from improving the self-esteem of audiences (BBC America and Women's Media Centre, 2018), to providing 'role models' that will model pathways into fields of education or work (Gill, 2016; Wood \& Litherland, 2018).

Notions that 'representation matters', an underlying logic of media and cultural studies scholarship for decades, has gone mainstream, but in so doing have shifted away from a structural political understanding of the mechanisms of representation. BanetWeiser traces a move from the feminist politics of visibility (where media representation was objected to as part of a political agenda) to 'economies of visibility', where the visibility of identities has become an end in itself (2015, p.56). An economy of visibility is one in which there is a profitable supply and demand for individuals and groups to be 'seen', 'heard' and represented, but with little accompanying political agenda. In a similar vein, Warner identifies 'plastic representation', where visible diversity on screen is emphasised 'in order to flatten the expectation to desire' greater transformation in the media industries (2017, p.35).

The value and importance of representation has been recognised by media corporations. Something of an innovator in this regard, Disney strategically places representation at the core of its Corporate Social Responsibility (CSR) strategy (Walt 
Wood, R., Litherland, B., and Reed, E. (2019) Cultural Studies.

Disney Company, 2017). CSR allows corporations to signal their socially or environmentally beneficial impacts while aligning them with profit driven goals (Vogel, 2007). Literature on CSR primarily explores corporate programmes for practices such as reducing carbon emissions or paying workers fairly (Vogel, 2007), but representation increasingly features within the CSR strategies of media corporations. Disney has historically stressed diversity of staff and audiences, but less so the importance of representation (see The Walt Disney Company, 2011). Alongside stated commitments to 'environmental stewardship', 'international labour standards', and 'healthy living', Disney's 2017 CSR strategy pronounces the corporation's commitment to the 'authenticity' of representing characters and stories 'that reflect and engage our diverse, global community' (The Walt Disney Company, 2017, p. 11).

Since the 1980s, the discursive framing of Corporate Social Responsibility as not only compatible with profit, but a direct strategy of profit accumulation and growth, has been a major capitalist success story (Sandoval, 2014). Concurrently, mistrust of large corporations continues to grow, forged from anti-consumerism movements in the era of No Logo (1999) and accelerated by the increasing awareness of the climate crisis (Murdock, 2013). Representing 'feminist' and 'diverse' characters while selling corresponding merchandise to growing markets of socially conscious parents and fans (de Bruin-Molé, 2018), is one way to further cement the links between 'good' representations and corporate growth, while side-stepping responsibilities that might not align as neatly with capitalist expansion imperatives. For Disney, the largest media conglomerate globally, each property spans a vast range of transmedia texts with multiple sites of production, from films to theme parks, toys and comic books (Evans, 2011). The task of tracing and proving the ethical provenance, production conditions, and ethical and 
Wood, R., Litherland, B., and Reed, E. (2019) Cultural Studies.

environmental impact of each space, text and object is challenging in a way that branding the ideological meaning of a media brand is not.

At our most critical, then, we might say the corporate move towards the ethics of representation serves as a veneer through which corporations can claim to 'do good' while moving scrutiny and critique away from altogether more complex and harder to (profitably) deliver responsibilities. Without losing sight of these important critiques of the corporate turn to 'ethical' representation, it is clear from families' responses that some audiences do endeavour to make choices about the media they consume drawing on notions of 'ethics'. Thus, they participate in and consume culture not only with an eye for entertainment, pleasure, routine, identity building, and so on, but also, as part of a selfdefined ethical project - with the hope and expectation that this can achieve both individual and social good. By consuming and culturally participating in 'good' texts families understand that they are doing something right, for themselves, their daughters, and - implicitly and sometimes explicitly - for society more broadly.

\section{Consuming 'ethically'}

Whether through consumer 'buycotts' or the purchasing of fair trade, the idea of doing political or social 'good' through consumption is not new. With roots in co-operative movements and alternative lifestyles, since the late 1980s the phrase ethical consumerism or ethical consumption has developed to capture a set of consumer practices which attempt to remove or mitigate through consumer choice the worst excesses of capitalist exploitation within the chain of commodity production (Littler, 2008). Ethical consumption involves the search for imperfect solutions within the inherently unjust practices and structures of consumer capitalism (Littler, 2008).

Ethical cultural consumption, we suggest, involves an investment in individual and social change, and the imagining of a better, more equitable world through the 
Wood, R., Litherland, B., and Reed, E. (2019) Cultural Studies.

consumption of a cultural text. We return in the conclusion to the effectiveness of this claim, and the range of practices to which the model of ethical cultural consumption might be applied. Where ethical consumption research has highlighted the individualised forms of 'self-fashioning' central to the practice, where a sense of morality is directed inwards, towards becoming a better person (Littler, 2008, p. 8), ethical cultural consumption further centralises the individual as the 'beneficiary' of 'good' consumer choices (BanetWeiser \& Mukherjee, 2012, p. 12). As scholarship on ethical consumption emphasises, however, we need to remain critical without condemning or dismissing the political potential of consumption (Banet-Weiser \& Mukherjee, 2012; Littler, 2008). Indeed, Barnet et al. (2010) suggest we attend to the ways ethical consumption has reoriented, and continues to shape, what it means to 'be political', with consumers becoming aware of their social responsibilities and obligations as 'consumer citizens' (Banet-Weiser, 2007). While consuming culture may involve a consideration of exploitation or inequality within a chain of production in the media industry (Cocca, 2016; Hunt, 2018), our research responses suggest that this not the only, or even primary, way to ethically consume culture. Instead, ethical cultural consumers understand themselves among an imagined audience who are the beneficiaries of ideologically 'good' representation.

There are further questions about the relationship between ethical consumption, which, at least on the surface, emphasizes and seeks to make visible and improve the conditions of production, and ethical cultural consumption, which operates more comfortably in the symbolic and ideological register. For example, Rey merchandise is still produced in an industrial capitalist system involving human and environmental exploitation, made by workers in emergent economies and potentially employing harmful processes, materials and practices. What 'good' is being achieved by, for instance, purchasing a disposable children's costume with plastic accessories and packaging, made 
Wood, R., Litherland, B., and Reed, E. (2019) Cultural Studies.

in a factory by exploited workers? Ethical cultural consumption does not necessitate an awareness of these conditions, though it does not necessitate a disavowal either. Interestingly, four of the nine families who participated in this research made rather than purchased their costumes, with one parent noting the satisfaction of creating 'something pretty impressive out of stuff we had around the house' (Family 3 ). This suggests that there may be intersections between the discourses and practices of ethical consumption and ethical cultural consumption that are worthy of exploration. In this sense, ethical cultural consumption as a concept captures the tensions and potential overlap between material and media consumption in a way plastic representation (Warner, 2017) - which also seeks to describe the visibility of 'good' representation, but where 'plastic' is mobilised only as metaphor - might not.

Parenting girls in popular feminism is a productive site - although not the only potential site - for interrogating ethical cultural consumption. In the context of this research, our participants' 'ethical' choices are deeply inflected with neoliberal notions of individual responsibility and risk management that underscore cultures of contemporary parenting in popular feminism. We are interested in interrogating the specifics of the 'good' that participants perceive they might achieve through consumption of Rey. As we examine in the following section, much of this 'good' centres on the branding of Rey's key character qualities. As Gill and Orgad (2018a, p.478) argue, there has been an intensified emphasis in contemporary austerity capitalism on qualities and dispositions of character, including resilience and confidence, seen as necessary for middle class girls and women in particular 'to survive and thrive'.

The need to equip girls with resilience was a clear theme in participating families' responses. As one parent stated: 'The one thing I teach my two girls is don't let a road block stop you, just keep going. They know there will always be challenges, things don't 
Wood, R., Litherland, B., and Reed, E. (2019) Cultural Studies.

happen overnight and it takes a lot of hard work' (Family 7). Consuming the right cultural texts was one way in which parents endeavoured to model these characteristics, with one parent seeking out characters who possess 'tenacity, kindness, patience, strength, not to give up' (Family 4). Other parents evidence these investments in Rey specifically:

[Rey] doesn't give in or give up (Family 5)

[Rey] has vulnerabilities and feelings, and tries to overcome them by being independent and brave. (Family 1)

Rey is being used here, among other media representations, as a tool to determine the right outcome of raising a girl: a successful and resilient young woman (McRobbie, 2009). Rey serves as a shared set of clear character signifiers that girls and families can draw upon through costume play in order to co-construct the 'right' kind of femininities and family identities. In the following analysis, we examine families' perceptions of Rey as a brand shown in their responses and drawings, before turning in the final section to the perceived positive impact of Rey costume play in girls' everyday lives.

\section{'Kind, Brave and Strong': Being a Girl Like Rey}

Rey's representation allows families to carefully navigate a series of almost impossible contradictions within contemporary discourses in popular feminism: feminine, but not 'too' pretty or girly; brave and strong, but not 'like a man'; gently critiquing normative representations of gender while reassuringly reinforcing them. In this section, we explore the consensus, and some differences, in describing and negotiating Rey's femininity among girls and parents who participated in the project.

Girls' drawings showed a consistent awareness of the visual markers that distinguish Rey [see Fig 1 and 2 for examples of this], including: wrap dresses and triple bun hairstyles (6 of the 9 drawings); utilitarian shoes or boots ( 7 of the 9 drawings); and arm wraps (2 of 9). 8 of the 9 drawings depicted Rey holding a lightsabre [Fig.1], or staff, 
Wood, R., Litherland, B., and Reed, E. (2019) Cultural Studies.

or both [Fig.2]. Given the consistent visual branding of Rey this is perhaps not surprising, but what was notable was the consistency with which Rey's character qualities were also identified.

[Insert Figure 1 about here. Caption: Drawing by Family 3]

When asked the three best things about Rey, one girl reportedly responded, "she is kind, brave and strong" (Family 2), qualities often repeated in various configurations. Parents related that their daughters had stated "she's strong and fights bad guys" (Family 5); "she is strong and ready to fight" (Family 9); and "I like her and she's brave. I'd say she's fearless or something” (Family 1). One girl depicted Rey saying, "I am so strong!!!” on her drawing (Family 4). While references to fighting appear to refer to physical strength, one parent reported that their daughter described this strength as being "in her head" (Family 8). Strength and bravery were therefore understood as valuable character qualities.

Kindness, the third quality identified, encompassed a range of often feminine coded values such as caring, generosity, forgiveness, empathy and compassion. One girl reportedly stated that Rey is the type of person she would like to be because 'she is kind and forgives everybody, and gives everybody a second chance' (Family 4). Kindness was often mentioned by participants in combination with the more masculine coded qualities of strength and bravery. Several parents gave responses that captured this blending of attributes:

Rey is strong and also sensible. She is kind. She is sure of herself but not arrogant. It is this balance of strength and humanity that I love the most (Family 4) 
[Rey is] a strong woman who is not afraid to stand up for what she believes in, but at the same time she does have a vulnerable side. She shows kindness compassion and understanding (Family 6)

Rey is strong but caring and wants to do what is right (Family 5)

Here kindness appears to be framed as a kind of tempering influence on potentially more headstrong, brute, masculine forms of strength and bravery. Rey's form of heroism is explicitly valued for its thoughtfulness and compassion towards others, with one parent stating Rey is a 'good friend' as well as a strong fighting hero (Family 2). Rey's heroism is social, and her brave actions are thoughtful of potential consequences, as one girl expressed particularly clearly: '[Rey] thinks about what she needs to do to be brave. She talks to others about plans that they will make and that they will do them' (Family 1). This combination of strength, bravery and kindness appears to offer a critique of traditional masculine heroism. Bravery is valued less as an inherent trait than a resource that can and should be drawn upon thoughtfully, kindly, and through conversation with and consideration for others.

There was one area of divergence in parents and girls' accounts of Rey's qualities. Parents saw Rey as an alternative to very feminine, appearance-centric representations of women elsewhere in the media:

Many female characters in movies or books are skinny, beautiful and sometimes helpless. Female superheroes are put in skimpy clothing and there is more focus on their appearance than their character. (Family 5)

'Princess' media was disliked among parents, one of whom objected to 'endless princess fantasies' in media texts (Family 1). Despite her normatively attractive (slim, young, white) feminine appearance, parents repeatedly stressed Rey was something of an alternative to pretty, princess centric role models for girls. As one parent stated, 'this is 
Wood, R., Litherland, B., and Reed, E. (2019) Cultural Studies.

what we really like about the role model of Rey. Although thin, she is not represented as a female with big breasts [and] the usual physical attributes that often bombard girls' (Family 9). This suggests an attempt to ideologically inoculate girls against hyperfeminine 'over the top' 'girly' femininities, warding off the spectre of the 'at risk' girl (Harris, 2004) and producing the respectable middle class family through distinction (Bourdieu, [1984] 2013; Skeggs, 1997; Jensen, 2018).

In contrast to parental framings, however, girls' reported responses implied that they do not understand Rey to be distinct from 'pretty' princesses (Booth, forthcoming) to the degree their parents do. Rey's 'pretty' hairstyle and 'beautiful' appearance were praised in girls' responses, and drawings showed Rey smiling and with exaggerated feminine eyes and eyelashes in a style familiar from children's cartoons [Fig.2].

[Insert Figure 2 about here. Caption: Drawing by Family 2]

Unlike parents, girls focused on the importance of Rey's droid 'sidekick' BB8, with BB8 appearing in three drawings [Fig.2]. The presence of a cute sidekick, along with her pretty hair and appearance, appears to align Rey with Disney Princess branding for girls, if not their parents. At the same time, Rey was not seen as a character just 'for girls', with responses describing participation and play with male relatives. Two girls described Rey as 'cool' (Family 3 and 6) and another said that dressing as Rey makes her 'look cool' (Family 5). There is something grown-up, impressive and not traditionally feminine about being a girl who dresses as Rey, while the character still retains reassuringly feminine branding for girl consumers (Cann, 2018).

It is important to acknowledge the evident pleasure and value that families appeared to gain from consuming and being Rey. For example, families spoke of shared 
Wood, R., Litherland, B., and Reed, E. (2019) Cultural Studies.

family time and intergenerational fan interests (Barker et al, 2016). Moreover, it is crucial to recognise that families are operating in a context in which the available cultural representations of and for girls, from Barbie to Disney Princesses, tend to be gendered in highly restrictive, normative and binary ways (Reed, 2018). The values of strength, bravery, kindness and prettiness attributed to Rey do, to some extent, create space for emergent popular feminist infused critiques of femininity. It remains important not to shut down the transformative, even resistant, possibilities Rey enables for families and girls.

\section{Transforming Everyday Girlhood}

In this section, we explore how the project of ethical cultural consumption plays out in everyday life, focusing on the forms of transformation that were attributed to Rey's influence by both girls and parents. Responses to questions about play and behaviour during costume play invoked difference, change, or transformation of the everyday:

"She gets very serious, which isn't her 'normal' behaviour" (Family 5)

"For [posing for] pictures she's serious and strong" (Family 7)

"She becomes fearless and doesn't let anything stand in the way of the task ahead...she'll do things she wouldn't normally do, like climbing a wall, swinging off a wall” (Family 6)

Parents sought to highlight that their daughters did things which in everyday life they did not or could not otherwise; 'She is self-confident, which in everyday life she is not. She is unafraid whereas in real life she is scared of many things' (Family 4). Parents here evidence a belief that their curated ethical cultural consumption practices are already 'doing good' in their daughters' lives, imbuing transformational qualities of confidence and bravery.

Parents' reported comments from girls also echoed this. One girl said that Rey 'makes me feel strong and brave. When I am Rey I can have lightsabre fights with my 
Wood, R., Litherland, B., and Reed, E. (2019) Cultural Studies.

brother' (Family 2). Other girls identified the costume itself as the transformative object which 'makes me feel adventurous' (Family 1) or 'feel full of energy, strong' (Family 4). When 'struggling with homework' the costume reportedly allowed one girl to access 'the Force' and complete the task (Family 5). The Rey costume was a totem of transformation: an object which gave these girls a sense of being lifted from their everyday struggles and restrictions to a creative space (Rahman, Wing-sun, \& Cheung, 2012) in which they can 'channel' Rey's energy and strength to fight, be brave and adventurous, and overcome challenges. Rey appeared to offer a means by which they could communicate the flexibility of their selves (Dyson, 1997; Hains, 2012; Wohlwend, 2009).

These responses suggest that certain qualities are considered beyond the ordinary expectations of girlhood, and girls are imagined as stepping out of their everyday selves into these performances of Rey-ness. As Family 1 stated, Rey costume play gives their daughter a 'sense of possibility, that she can be brave too'. By contrast, when asked about their daughters' personalities, almost all participants described feminine coded qualities including kindness, compassion, empathy and creativity. It was only the performance of strength, confidence, aggression, and assertiveness which participants attributed as transformative aspects of Rey-play.

Prevailing discourses of femininity and girlhood in the contemporary social landscape limit the possibilities for girls' alternative, hybrid identities to be recognised (Driver, 2007; Wohlwend, 2009, p. 58). For girls, wearing a Rey costume may be an opportunity to experiment with performances of her embedded branded qualities, but was also a route by which they might be recognised for possessing these characteristics by adults who are familiar with the meanings of the costume. The girls' deployment of Rey to authorise and make comprehensible behaviour which may deviate from cultural assumptions surrounding girls' 'natural' or inherent qualities, could indicate girls' 
Wood, R., Litherland, B., and Reed, E. (2019) Cultural Studies.

flexible and creative use of cultural scripts (Lupold, 2014), and their active engagement in [per]forming their hybrid identities.

Ultimately, given the co-constructed and filtered nature of survey responses from parents and girls, the ways in which girls were using Rey costume play remain ambiguous. Our findings suggest the need for further ethnographic research on children's costume play, and argue that such research is particularly needed to explore these uses of media texts in families, in the same way much ethnographic research has already considered children's communication through, consumption, and use of, media texts in educational settings (Dyson, 1997; Hains, 2012; Marsh, 2000; Read, 2010; Wohlwend, 2009 for e.g.) and within peer cultures (Buckingham \& Sefton-Green, 2003; Driver, 2007; Suess et al., 1998)

Characterisation of Rey-play as transformative draws upon the deterministic frameworks that underscore a project of moulding 'better' girls through ethical cultural consumption. The idea that girls require role models to introduce them to strength and bravery suggests a somewhat rigid and mimetic model of girlhood and identity. For parents, it may be that attributing transformative potential to Rey costume play in their daughter's lives affirms the efficacy of their efforts. This perceived self-fulfilment of parents' endeavours is perhaps inevitable given the contingency, intangibility and ambiguity of ethical cultural consumption. Consuming culture 'ethically' in this way necessitates an uncertain investment in future oriented hopes. Given the risk awareness that saturates contemporary life, parents may attempt to achieve feelings of control through those choices that are readily available to them - namely consumer choices. Ethical cultural consumption must necessarily hope to imbue individual agency with an impossible level of influence and power to shape not only individual futures, but broader programmes of social and cultural change. 
Wood, R., Litherland, B., and Reed, E. (2019) Cultural Studies.

\section{Conclusion}

This paper has made the case for understanding families' consumption of Rey as part of a broader set of practices that can be described as ethical cultural consumption. For these families, consuming culture is part of a project of building a better, more equal world. It is a social and political project, albeit one understood through a highly individualised lens. An embrace of ethical cultural consumption speaks to the limited range of options and opportunities available to affect social and political change in neoliberalism. Similarly, ethical consumption discourses inevitably inflate the ability of consumer choice to act as a catalyst for halting the advance of climate change or improving working conditions. With ethical cultural consumption it becomes even murkier to quantify the 'good' that is being achieved. As parents' perceptions of their daughters' transformations show, success or failure is predominantly in the eye of the beholder, allowing parents to shore up their hopes to determine a positive future and a better, fairer world.

At the same time, it is crucial not to be dismissive of the politics at play in ethical cultural consumption. As decades of Media and Cultural studies scholarship has shown, representation does matter a great deal, and it continues to have the potential to contribute to shaping social perceptions and inequalities for good or ill (Dyer, 2002). As explored in family's negotiations of Rey's kindness, strength and bravery, this popular character does allow girls and parents to engage in a subtle critique of both hegemonic masculine heroism and passive feminine representation. In the context of often restrictive and normative gender binaries in children's toys and media, girls embrace Rey's branding as a remodelled princess, and a 'cool' brave, strong, yet compassionate hero, using this to explore hybrid gender identities and performances that can be intelligibly communicated and shared with parents. 
Wood, R., Litherland, B., and Reed, E. (2019) Cultural Studies.

The politics of ethical cultural consumption are clearly constrained by a range of factors: the production and availability of these 'good' representations is ultimately contingent on their profitability; the individual consumer's ability to affect social change through their participation in consumer capitalism is limited; the nature of the line being drawn between consuming culture and tackling social inequalities remains almost deliberately vague; and the material conditions in which consumer products are produced and manufactured can easily be obscured from view when focusing on textual meaning. It is now a common sense of neoliberal media cultures that citizenship is practiced and understood through consumption (Banet-Weiser, 2007), and that those social groups that can be conceived of as markets are conferred visibility and rights as civic publics. Ethical cultural consumption takes consumer citizenship one step further, as actors aim to enact an individualised version of social change through the consumption of culture. It remains crucial to theorise such a politics on its own terms, and not only in comparison to some nostalgic ideal politics (Benet-Weiser, 2004). We therefore remain critically hopeful about some of the possibilities enabled by ethical cultural consumption.

While ethical cultural consumption has been explored in this paper in relation to popular feminism, girlhood and families, we suggest this is a highly productive concept for framing a range of cultural phenomena. Contemporary popular culture abounds with expressions of consumer investment in the individual and socio-political potential to 'do good' and affect change through consuming media culture from comic books and movies, to Netflix shows and YouTube creators. Popular discourses, including 'problematic faves' (McBride, 2017) and 'cancel culture' (Garel, 2018), along with discussions of supporting or boycotting media representations and texts, all suggest that the ethics of representation and consumption have strong cultural currency. \#MeToo has brought practices of ethical cultural consumption to the fore at the same time as bringing some 
Wood, R., Litherland, B., and Reed, E. (2019) Cultural Studies.

exploitative and abusive production practices and power dynamics to light, raising questions about the links between 'good' representations and cultural producers. The model of ethical cultural consumption we have developed here might enable scholarship to critically explore the ways in which consumer efforts to 'do good' through consuming and participating in culture are framed and understood, while investigating the contradictions, constraints and (im)possibilities they engender.

\section{Funding Details}

This work was supported by the Goldsmiths Sociology Research Development Fund and The University of Huddersfield University Research Fund.

\section{References}

Baer, H. (2016). Redoing feminism: digital activism, body politics, and neoliberalism. Feminist media studies, 16(1), 17-34.

Banet-Weiser, S. 2004. Girls rule!: Gender, feminism, and Nickelodeon. Critical Studies in Media Communication, (21) 2, 119-139.

Banet-Weiser, S. 2007. Kids rule!: Nickelodeon and consumer citizenship. Durham: Duke University Press.

Banet-Weiser, S. 2015. Keynote address: Media, markets, gender: Economies of visibility in a neoliberal moment. Communication Review, 18 (1), 53-70.

Banet-Weiser, S. 2015. Popular misogyny: A zeitgeist. Culture Digitally, Available from: http://culturedigitally.org/2015/01/popular-misogyny-a-zeitgeist/ [accessed 30 October 2018]

Banet-Weiser, S. and Mukherjee, R. 2012. Commodity Activism: Cultural Resistance in Neoliberal Times. New York: New York University. 
Wood, R., Litherland, B., and Reed, E. (2019) Cultural Studies.

Banet-Weiser, S., Gill, R., \& Rottenberg, C. (2019). Postfeminism, popular feminism and neoliberal feminism? Sarah Banet-Weiser, Rosalind Gill and Catherine Rottenberg in conversation. Feminist Theory, 1464700119842555.

Barker, M., Egan, K., Ralph, S. and Phillips, T. 2016. Alien Audiences: Remembering and Evaluating a Classic Movie. London: Palgrave.

BBC America and Women's Media Centre. 2018. SuperPowering girls: Female representation in the sci-fi/superhero genre. Available from:

http://www.womensmediacenter.com/reports/bbca-wmc-superpowering-girls [accessed 31 October 2018]

Bland, D. 2012. Analysing children's drawings: applied imagination. International Journal of Research \& Method in Education. 35 (3), 235-242.

Blodgett, B. and Salter, A. 2018. Ghostbusters is for boys: Understanding geek masculinity's role in the alt-right. Communication Culture \& Critique. 11 (1), 133146.

Booth, P. Forthcoming. Disney's Princess Leia. In W. Proctor, and R. McCulloch, eds. Disney's Star Wars: Forces of Production, Promotion and Reception. Iowa: University of Iowa Press.

Bourdieu, P. 2013. Distinction: A Social Critique of the Judgement of Taste. London: Routledge.

Buckingham, D. and Sefton-Green, J. 2003. Gotta Catch 'em all: Structure, Agency and Pedagogy in Children's Media Culture. Media, Culture and Society. 25(3), 379-399 Braun, V. and Clarke, V., 2013. Successful qualitative research: a practical guide for beginners. London: Sage 
Wood, R., Litherland, B., and Reed, E. (2019) Cultural Studies.

Brown, J.A. 2017. \#WheresRey: Feminism, protest, and merchandising sexism in Star Wars: The Force Awakens. Feminist Media Studies. 18 (3), 335-348.

Cann, V. 2018. Girls Like This, Boys Like That: The Reproduction of Gender in Contemporary Youth Cultures. London: IB Tauris.

Chudacoff, H. P. 2007. Children at Play: An American History. New York: NYU Press.

Cocca, C. 2016. Superwomen: Gender, Power, and Representation. New York:

Bloomsbury Publishing.

de Bruin-Molé, M. 2018. " Does it Come with a Spear?" Commodity Activism, Plastic Representation, and Transmedia Story Strategies in Disney's Star Wars: Forces of Destiny. Film Criticism, 42(2).

Driver, S. 2007. Queer Girls and Popular Culture: Reading, Resisting and Creating Media. New York: Peter Lang.

Dyer, R. 2002. The Matter of Images: Essays on Representation. London: Psychology Press.

Dyson, A. Haas. 1997. Writing Superheroes: Contemporary Childhood, Popular Culture, and Classroom Literacy. New York: Teachers College Press.

Einarsdottir, J. 2007. Research with children: methodological and ethical challenges. European Early Childhood Education Research Journal. 15 (2), 197-211.

Evans, E. 2011. Transmedia television: Audiences, new media, and daily life. London: Routledge.

Flaherty K and Rackham C (2016) Little girls went to comic-con dressed as Rey and that's so important. Buzzfeed, 24 Jul. Available from: 
Wood, R., Litherland, B., and Reed, E. (2019) Cultural Studies.

https://www.buzzfeed.com/keelyflaherty/little-girls-went-to-comic-con-dressed-as-rey-

and-thats-so-i [accessed 25 October 2018]

Gallagher, M. 2009. Data collection and analysis. In EKM, Tisdall, JM Davis and M

Gallagher, eds. Researching with Children and Young People: Research Design,

Methods and Analysis. London: Sage, 65-84.

Garel, C. 2018. Logan Paul and the myth of cancel culture. Vice, 10 July. Available from: https://www.vice.com/en_uk/article/8xb9x5/logan-paul-and-the-myth-of-cancelculture [accessed 31 October 2018]

Gill, R. 2007. Postfeminist media culture: Elements of a sensibility. European Journal of Cultural Studies. 10 (2), 147-166.

Gill, R. 2016. Post-postfeminism?: New feminist visibilities in postfeminist times. Feminist Media Studies. 16 (4), 610-630.

Gill, R. and Orgad, S. 2018a. The amazing bounce-backable woman: Resilience and the psychological turn in neoliberalism. Sociological Research Online. (23) 2, 477-495.

Gill, R., \& Orgad, S. 2018b. The shifting terrain of sex and power: From the 'sexualization of culture’to\# MeToo. Sexualities, 21(8), 1313-1324.

Hains, R.C. 2012. An afternoon of productive play with problematic dolls: The importance of foregrounding children's voices in research. Girlhood Studies. 5 (1), 121-140.

Harris, A. 2004. Future Girl: Young Women in the Twenty-First Century. London: Routledge. 
Wood, R., Litherland, B., and Reed, E. (2019) Cultural Studies.

Hunt, W. 2018. Negotiating new racism: 'It's not racist or sexist. It's just the way it is'. Media, Culture \& Society. Epub ahead of print 4 October 2018. DOI:

$10.1177 / 0163443718798907$

Jensen, T. 2018. Parenting the Crisis: The Cultural Politics of Parent-Blame. Bristol: Policy Press.

Karvelas, P. 2015. Star Wars is a game-changer, awakening the feminist force in little girls everywhere. The Guardian. Available from:

www.theguardian.com/commentisfree/2015/dec/30/star-wars-is-a-game-changerawakening-the-feminist-force-in-little-girls-everywhere [accessed 3 February 2017]

Klein, N. 1999. No Logo: Taking aim at the brand bullies. London: Picador.

Komulainen, S. 2007. The ambiguity of the child's 'voice" in social research.

Childhood. 14 (1), 11-28.

Lamerichs, N. 2018. Productive Fandom: Intermediality and Affective Reception in Fan Cultures. Amsterdam: Amsterdam University Press.

Lee, E. 2014. Introduction. In E. Lee, J. Bristow, C. Faircloth, and J. Macvarish, eds. Parenting Culture Studies. Basingstoke: Palgrave, 1-22.

Littler, J. 2008. Radical Consumption: Shopping For Change In Contemporary Culture: Shopping for Change in Contemporary Culture. London: McGraw-Hill Education.

Lupold, E. 2014. Adolescence in action: Screening narratives of girl killers. Girlhood Studies. 7 (2), 6-24.

Marsh, J. 2000. But I want to fly too!: Girls and superhero play in the infant classroom. Gender and Education, 12(2), 209-220. 
Wood, R., Litherland, B., and Reed, E. (2019) Cultural Studies.

McBride, C. 2017. What is a problematic fave? The Mary Sue, 18 October. Available from: https://www.themarysue.com/problematic-faves/ [Accessed 31 October 2018]

McRobbie, A. 2009. The Aftermath of Feminism: Gender, Culture and Social Change. London: Sage.

Murdock, G. 2013. Producing consumerism: Commodities, ideologies, practices. In Fuchs, C., \& Sandoval, M. (Eds.). Critique, social media and the information society. (pp. 137-155). New York, NY: Routledge.

Punch, S. 2002. Research with children: The same or different from research with adults? Childhood. 9 (3), 321-341.

Ratcliffe, A. 2016. Fully operational fandom: Becoming Rey. Star Wars. Available from: http://www.starwars.com/news/fully-operational-fandom-becoming-rey [accessed 3 February 2017]

Rahman, O., Wing-sun, L. and Cheung, H. 2012. "Cosplay": Imaginative self and performing identity. Fashion Theory. 16 (3), 317-342.

Read, B. 2010. Britney, Beyoncé, and me - primary school girls' role models and constructions of the 'popular' girl. Gender and Education. 23(1). 1-13

Reason, M. 2010. The Young Audience: Exploring and Enhancing Children's Experiences of Theatre. London: Institute of Education Press.

Reed, E. 2018. Lesbian, Bisexual and Queer Motherhood: Crafting Radical Narratives and Representing Social Change through Cultural Representations. Women: A Cultural Review. 29(1), 39-58.

Rottenberg, C. 2018. The Rise of Neoliberal Feminism. Oxford: Oxford University Press. 
Wood, R., Litherland, B., and Reed, E. (2019) Cultural Studies.

Sandoval, M. (2014). From corporate to social media: Critical perspectives on corporate social responsibility in media and communication industries. London: Routledge.

Scott, S. 2017. \#Wheresrey?: Toys, spoilers, and the gender politics of franchise paratexts. Critical Studies in Media Communication. 34 (2), 138-147.

Skeggs, B. 1997. Formations of Class and Gender: Becoming Respectable. London: Sage.

Smith, B. 2017. Generalizability in qualitative research: misunderstandings, opportunities and recommendations for the sport and exercise sciences. Qualitative Research in Sport, Exercise and Health. 10 (1). 137-149

Steinmetz, G. 2004. Odious Comparisons: Incommensurability, the Case Study, and “'Small N's”' in Sociology. Sociological Theory. 22 (3). 371-400.

Suess, D., Suonien, A., Garitaonandia, C., Juaristi, P., Koikkalainen, R. and Oleaga, J.A. 1998. Media Use and the Relationships of Children and Teenagers with their Peer Groups: A Study of Finnish, Spanish and Swiss Cases. European Journal of Communication. 13(4). 521-538.

The Walt Disney Company (2011) Corporate citizenship report 2010. Available from https://ditm-twdc-us.storage.googleapis.com/FY10Disney_2010_CC_Report.pdf [accessed 30 October 2018]

The Walt Disney Company (2017) Corporate social responsibility update 2017. Available from https://www.thewaltdisneycompany.com/wpcontent/uploads/2017disneycsrupdate.pdf [accessed 30 October 2018]

Vincent, C. and Ball, S.J. 2007. "Making up" the middle-class child: Families, activities and class dispositions. Sociology. 41 (6), 1061-1077. 
Wood, R., Litherland, B., and Reed, E. (2019) Cultural Studies.

Vogel, D. 2007. The Market for Virtue: The Potential and Limits of Corporate

Social Responsibility. Washington, D.C.: Brookings Institution Press.

White, S. 2016. The Darkside cannot have Rey. Talk Star Wars, 23 November.

Available from: https://www.talkstarwars.co.uk/news/the-darkside-cannot-have-rey

[accessed 3 February 2017]

Wohlwend, K.E. 2009. Damsels in discourse: Girls consuming and producing identity texts through Disney Princess play. Reading Research Quarterly. 44 (1), 57-83

Wood, R., \& Litherland, B. (2018). Critical feminist hope: the encounter of neoliberalism and popular feminism in WWE 24: Women's Evolution. Feminist Media Studies. 18 (5), 905-922. 